\title{
A Platform for Closing the Open Data Feedback Loop based on Web2.0 functionality
}

\author{
Charalampos Alexopoulos*, Euripidis Loukis*, Yannis Charalabidis*
}

\author{
* University of the Aegean, Department of Information and Communication Systems Engineering, Greece, \{alexop, eloukis, \\ yannisx\}@aegean.gr
}

\begin{abstract}
One essential characteristic of open data ecosystems is their development through feedback loops, discussions and dynamic data users-suppliers interactions. These user-centric features communicate the users' needs to the open data community as well to the public sector organizations responsible for data publication. Addressing these needs by the corresponding public sector organizations, or even by utilising the power of the community, can significantly promote and accelerate innovation. However, such elements appear barely to be part of existing open data practices in the public sector. In this paper we describe and discuss an open data platform, which contributes to filling this gap, by providing Web 2.0 functionality that supports and intensifies open data users-suppliers interactions, and then we present a usage scenario of it, explaining the sequence of using its functionality. The discussed open data infrastructure combines functionalities that aim to close the feedback loop and to return information to public authorities that can be useful for better government data opening and publication, as well as for establishing communication channels between all stakeholders that fosters their collaboration. This may effectively lead to the stimulation and facilitation of value generation from open data, as such functionality positions the user at the centre of the open data publication process.
\end{abstract}

Keywords: open government data, public sector information, e-infrastructures, Web 2.0, social media

Acknowledgement: The authors would like to thank their colleagues of the ENGAGE project for their input for this paper (see www.engage-project.eu and www.engagedata.eu.), although the views expressed are the views of the authors and not necessarily of the project.

\section{Introduction}

G overnments create and collect large amounts of data in various domains, such as business, tourism, health, pollution, traffic, unemployment, crime and poverty data. If these data are released to the public they can be used for many other purposes, which may be different from the ones of their initial creation, including various scientific, commercial and political purposes. Open data have been hailed for their potential to generate public value, particularly through innovation, economic growth, and transparency (for instance, Blakemore \& Craglia, 2006; Charalabidis, Ntanos, \& Lampathaki, 2011; European_Commission, 2003, 2011; Zhang, Dawes, \& Sarkis, 2005).

In order be able to benefit from open government data and generate value from them, several researchers have argued that opening and using these data should be seen as an on-going process performed by an ecosystem of multiple collaborating entities (Pollock, 2011; Zuiderwijk, Janssen, Choenni, Meijer, \& Sheikh_Alibaks, 2012). Pelet (2013) states that currently open data is an early experiment of a promising idea, and that it is important to understand that an effective open data program requires time and patience to grow. The open data ecosystem is "a multi-level and multi-dimensional entity where raw material, as far as distribution and developing are concerned, is the target of cooperation" (Poikola, Kola, \& Hintikka, 2011, p. 13). Open data ecosystems are characterized by the interaction of data producers, infomediaries as intermediate 
consumers of data or service providers and open data users (Ding, Peristeras, \& Hausenblas, 2012; Ubaldi, 2013). They consist of multiple interdependent socio-technical levels, and elements.

One essential element of open data ecosystems concerns their development "through user adaptation, feedback loops and dynamic supplier and user interactions and other interacting factors" (Zuiderwijk et al., 2014). Open data ecosystems perform data production and usage cycles with feedback loops, sharing of data back to publishers and also with the so-called infomediaries (Pollock, 2011). However, discussion and feedback loops appear barely to be part of existing open data practices and infrastructures. Zuiderwijk and Janssen (2013) found that after open data have been used, the provision of feedback to data providers or a discussion with them is quite important by not facilitated by existing open data infrastructures, though such mechanisms might be useful for improving open data quality, data release processes and policies. Dawes and Helbig (2010) found that such mechanisms can help users to obtain insight in how they can use and interpret open government data and generate value from them.

At the same time another major trend in government agencies has been the exploitation of Web 2.0 social media for increasing citizens' participation in the government decision and policy making processes, supporting networking, interaction and collaboration, and also collecting opinions, knowledge and ideas from citizens, and promoting government transparency and accountability (Bertot, Jaeger, \& Grimes 2012; Bonsón, Torres, Royo, \& Flores, 2012; Chun, \& Luna Reyes 2012; Margo, 2012; Criado, Sandoval-Almazan, \& Gil-Garcia, 2013). Therefore it would be interesting to investigate the use of Web 2.0 social media oriented capabilities in open government data platforms for the collection of feedback from their users, and in general for enabling and promoting discussion both between providers and users, and among users, in order to facilitate value generation from them and accelerate innovation.

In this paper initially in the following section 2 we outline the background of our research. Next in section 3 we present the functionality of an open government data platform developed in the European project ENGAGE ${ }^{1}$, which aims to contribute to filling the above identified gaps concerning citizens' feedback mechanisms, and then in section 4 we provide a usage scenario explaining the sequence of using its functionality. Finally, in the final section 5 the conclusions are summarized and future research directions are proposed.

\section{Background}

The Web 2.0 has been developed as a 'paradigm change' in the use of the Internet, which promotes the extension of content generation beyond the experts and the professionals to the simple and non-expert users, and also the rating and commenting of this content by other users, the collaboration and co-creation of content, the social networking and the development of online communities, which allow to their members to see profile information about the people to whom they are connected, and to share information and have extensive interaction with them ( $O$ ' Reilly, 2007; Davis \& Mintz, 2009).

The above capabilities were initially exploited by private sector firms, mainly as part of their marketing, new products development and customer service activities, leading to important transformations both within and outside firms' boundaries (Constantinides, \& Fountain, 2008; Goh, Heng, \& Lin, 2013; Aral, Dellarocas, \& Godes, 2013). It was much later that government agencies started adopting and utilizing social media for increasing citizens' participation and engagement in public policy making, for providing to more groups a voice in discussions of policy development, implementation and evaluation, promoting transparency-accountability, and also for crowdsourcing solutions and innovations, by exploiting public knowledge and talent in order to develop innovative solutions to the increasingly complex societal problems, and for public services co-production, by enabling government agencies and the public to develop and design jointly government services (Bertot, Jaeger, \& Grimes 2012; Bonsón, Torres, Royo, \& Flores, 2012; Chun, \& Luna Reyes 2012;

'http://www.engagedata.eu 
Margo, 2012; Criado, Sandoval-Almazan, \& Gil-Garcia, 2013). Highly influential in this direction have been central top-down initiatives in several countries, such as the 'Open Government Directive' in USA (Executive Office of the President, 2009), which defines three main pillars of open government: transparency (promoting accountability by providing the public with information about what the government is doing), participation (allowing members of the public to contribute ideas and expertise, so that their government can benefit from information and knowledge that is widely dispersed in society, in order to design better policies), and collaboration (improving the effectiveness of government by encouraging partnerships and cooperation within the federal government, across levels of government, and between the government and private institutions). Therefore opening government data for promoting transparency, and use of social media for increasing citizens' participation, are moving in the same direction, being both dimensions of the above open government concept; therefore, it would be interesting to investigate ways of combining them, so that one strengthens the other. The research conducted in the abovementioned ENGAGE project, part of which is presented in this paper, aims to make a contribution towards this combination.

\section{ENGAGE Platform Functionality}

In this section we present the ENGAGE platform functionality divided into two main categories: the first includes the classical ones, mainly, data publication-upload and modelling (metadata) for the data providers, and data search, visualization and download for the data users (see Table 1 for more details), while the second includes the novel ones based on the capabilities provided by Web 2.0 social media. These novel functionalities includes users' groups formation and extensive communication and collaboration within them, data processing, enhanced data modelling (flat, contextual and detailed metadata), commenting existing datasets and expressing needs for new datasets, datasets quality rating, data linking, publication/ upload of new versions of existing datasets, advanced data visualization (see Table 2 for more details).

Table 1: Classical Functionalities

\begin{tabular}{|l|l|l|l|}
\hline & Functionality & Stakeholder & Description \\
\hline $\mathbf{1}$ & $\begin{array}{l}\text { Data } \\
\text { Publication/upload }\end{array}$ & Provider & Support for publication/upload of datasets by providers \\
\hline $\mathbf{2}$ & Data Modelling & Provider & $\begin{array}{l}\text { Capabilities of flat metadata descriptions (based on a } \\
\text { specific metadata models) }\end{array}$ \\
\hline $\mathbf{3}$ & Data Search & User & $\begin{array}{l}\text { Simple search via keywords, resource format, publisher, } \\
\text { topic categories and countries }\end{array}$ \\
\hline $\mathbf{4}$ & Data Visualisation & User & $\begin{array}{l}\text { Simple visualisation techniques on specific datasets } \\
\text { (maps, charts) }\end{array}$ \\
\hline $\mathbf{5}$ & Data Download & User & $\begin{array}{l}\text { Data and metadata downloading capabilities - also } \\
\text { provision of API for this purpose }\end{array}$ \\
\hline
\end{tabular}

Table 2: Novel Web 2.0 Functionalities

\begin{tabular}{|l|l|l|}
\hline & Functionality & Description \\
\hline $\mathbf{1}$ & $\begin{array}{l}\text { Grouping and } \\
\text { Interaction }\end{array}$ & $\begin{array}{l}\text { Capabilities for: } \\
\text { (a) searching for users/providers having similar interests with us in order } \\
\text { to have knowledge exchange - cooperation, } \\
\text { (b) forming groups with other users/providers having similar interests with }\end{array}$ \\
\hline
\end{tabular}




\begin{tabular}{|c|c|c|}
\hline & & $\begin{array}{l}\text { us in order to have knowledge exchange - cooperation, } \\
\text { (c) maintaining datasets/working on datasets within one group, } \\
\text { (d) communicating with other users/providers through messages in order } \\
\text { to exchange knowledge, } \\
\text { (e) getting immediately updated about the upload of new versions and } \\
\text { enrichments of datasets maintained/worked on within the group, or new } \\
\text { relevant items (e.g. publications, visualizations, etc.). }\end{array}$ \\
\hline 2 & Data Processing & $\begin{array}{l}\text { Capabilities for: } \\
\text { (a) data enrichment (e.g. adding new elements - fields), } \\
\text { (b) for metadata enrichment (e.g. filling missing fields), } \\
\text { (c) for data cleansing (e.g. detecting and correcting ubiquities in a } \\
\text { dataset, matching text names to database IDs (keys) etc.), } \\
\text { (d) converting datasets to another format, } \\
\text { (e) submitting various types of items - e.g. visualisations, publications - } \\
\text { related to a dataset, } \\
\text { (f) datasets combination and mash-ups. }\end{array}$ \\
\hline 3 & & $\begin{array}{l}\text { Capabilities for description of flat, contextual and detailed metadata of } \\
\text { any metadata/vocabulary model. }\end{array}$ \\
\hline 4 & $\begin{array}{l}\text { Feedback and } \\
\text { Collaboration }\end{array}$ & $\begin{array}{l}\text { Capabilities for: } \\
\text { (a) communicating our own thoughts and ideas on the datasets to the } \\
\text { other users and the providers of them through comments on them, } \\
\text { (b) reading interesting thoughts and ideas of other users on the datasets } \\
\text { expressed through comments they enter on them, } \\
\text { (c) expressing our own needs for additional datasets that would be } \\
\text { interesting and useful to us, } \\
\text { (d) getting informed about the needs of other users for additional } \\
\text { datasets, } \\
\text { (e) getting informed about datasets extensions and revisions. }\end{array}$ \\
\hline 5 & $\begin{array}{l}\text { Data Quality } \\
\text { Rating }\end{array}$ & $\begin{array}{l}\text { Capabilities to (a) communicate to the other users and the providers the } \\
\text { level of quality of the datasets that I perceive, (b) get informed on the } \\
\text { level of quality of the datasets perceived by other users through their } \\
\text { ratings }\end{array}$ \\
\hline 6 & Data Linking & $\begin{array}{l}\text { Capabilities of data and metadata linking to other ontologies in the Linked } \\
\text { Open Data Cloud. } \\
\text { Capabilities of querying data and metadata through Sparql Endpoints. }\end{array}$ \\
\hline 7 & $\begin{array}{l}\text { Data New } \\
\text { Versions } \\
\text { Publication }\end{array}$ & $\begin{array}{l}\text { Support for publication/upload of new versions of the existing datasets, } \\
\text { and connection with previous ones and initial datasets. }\end{array}$ \\
\hline 8 & Data Visualisation & $\begin{array}{l}\text { Advanced visualisation techniques on specific datasets and/or datasets } \\
\text { mashups (maps, charts, plots and other) }\end{array}$ \\
\hline
\end{tabular}

\section{Usage scenario}

In this section we present a typical usage scenario that utilizes the functionality described in section 3, which illustrates how the ENGAGE platform can be used, focusing on its Web 2.0 social media oriented features (although as mentioned above the 'classical' features are also available, 
such as capabilities for uploading and downloading datasets). The usage scenario presented in this paper includes a number of steps that can be taken by a researcher who uses this open government data (OGD) platform:

- First, the researcher goes to the OGD platform, registers with one of his/her social media accounts (e.g. Facebook or Linkedln), searches for a particular dataset, views this dataset and has a look at how other users of the OGD platform have used it and also assess its quality.

- Taking into account what other users of the OGD platform wrote about how they have used (or can use) this dataset for similar purposes with the ones of the researcher (which is a very useful knowledge transfer among researchers), he proceeds with the analysis of the dataset, by visualising it through various tables and charts, and possibly on a map, and finally drawing conclusions from these analyses and visualizations.

- Subsequently, the researcher participates in discussions about the above dataset, by providing feedback or discussing the dataset, posting the conclusions that he has drawn from the use of it (in discussion areas accessible while viewing the dataset); all other users of the platform can see the messages that the researcher has posted and can respond to them by adding a message themselves, and in this way getting involved in the discussion. All these posted conclusions provide an overview of what has been learnt from the analysis of the dataset. This information is visible to any user of the OGD platform, including the providers of these data, who can also view this and assess how the data that they have opened are used.

- This allows also the government agency who has opened this dataset to gain of a better understanding of the value (commercial, social, political, scientific) that has been or can be generated from this datasets, which based on this makes decisions for the next datasets it will open.

- Also, the researcher uploads and associates with the original dataset the results of the use he/she has made of this dataset (i.e. a new dataset he/she has produced through processing the original dataset, and also publications, visualisations, applications and results based on these data).

- Next the researcher disseminates his/her findings by sharing them via social media (e.g. Twitter, Facebook, LinkedIn), linking the accounts used for this to the OGD platform; this helps him to make this research more visible to other researchers.

- Finally, the researcher has a look at the postings of all other users who have registered in the platform. He decides to send a private message to another platform user to discuss whether this other user would be interested in writing a joint paper in the future; if the other user agrees, they can create and open a closed group to work on the data processing together.

- They may also consider requesting the community to provide them with another additional dataset that the researcher wants to use in order to be able to write the publication; the OGD platform enables posting data requests, which can be answered by government organizations or other users of the platform.

- Also, the researcher might find persons interested to co-operate with him for developing a new commercial electronic service or mobile application that uses the above dataset, possibly in combination with other datasets

The above scenario shows how such a Web 2.0 OGD platform can be used in order to stimulate user interaction and collaboration, and finally value generation from them.

\section{Conclusions}

In this paper we initially discussed what feedback mechanisms (from open data users to providers) are provided by the existing open data infrastructures, and then describe how the ENGAGE open data infrastructure contributes to filling the identified gaps in bi-directional open 
data users - providers communication. Background research reveals that much can still be done in order to improve feedback and discussion in open data infrastructures. In this direction we described an open data infrastructure which contributes to filling this gap: the so-called ENGAGE open data infrastructure provides functionalities to close the feedback loop and return information from open data users to public authorities that can assist in improving open data publication, as well as in establishing communication channels between all open data stakeholders. In this direction the ENGAGE open data platform provides both 'classical' first generation open data functionalities as well as a comprehensive set of additional Web 2.0 social media oriented capabilities; the latter can be grouped into nine categories: 1) grouping and interaction, 2) data processing, 3) enhanced data modelling, 4) feedback and collaboration, 5) data quality rating, 6) data linking, 7) data new versions publication and 8) data visualisation. These additional novel functionalities may lead to the stimulation and facilitation of value generation from open data, as it is described from the usage scenario.

Further research is required in this direction, including the development of more advanced and mature versions of the platform, and its evaluation by various categories 'professional' users (e.g. researchers, journalists, politicians, value added services and application developers), in order to assess better the value it provides to each category, and identify possible weaknesses and required improvements. In particular, it would be quite interesting to investigate to what extent and how such a novel Web 2.0 oriented OGD platform can support the four types of OGD value generation mechanisms proposed by Jetzek et al. (2013): i) government efficiency gains (public sector organizations through OGD generate economic value by increasing their internal efficiency and effectiveness), ii) government transparency improvement (public sector organizations generate social value by offering increased transparency into government actions, which reduces 'information 'asymmetry' between government officials and citizens, which can lead to misuse of public power for private benefits and corruption), iii) private sector innovation (private sector firms generate economic value through the creation of new products and services using open government data, possibly, combining various types of them, from various government sources and also other private sector data as well), iv) private participation and collaboration (private sector firms generate social value through participating in the formulation of government policies and in general collaboration with government).

\section{References}

Aral, S., Dellarocas, C., \& Godes, D. (2013). Introduction to the Special Issue-Social Media and Business Transformation: A Framework for Research. Information Systems Research, 24(1), 3-13.

Bertot, J. C., Jaeger, P. T. and Grimes J. M. (2012). Promoting transparency and accountability through ICTs, social media, and collaborative e-government. TransformingGovernment: People, Process and Policy, 6(1), 78 - 91.

Blakemore, M., \& Craglia, M. (2006). Access to Public-Sector Information in Europe: Policy, Rights and Obligations. The Information Society, 22(1), 13-24.

Bonsón, E., Torres, L., Royo, S. and Flores, F. (2012). Local e-government 2.0: Social media and corporate transparency in municipalities. Government Information Quarterly, 29, 123-132.

Charalabidis, Y., Ntanos, E., \& Lampathaki, F. (2011). An architectural framework for open governmental data for researchers and citizens. In M. Janssen, A. Macintosh, J. Scholl, E. Tambouris, M. Wimmer, H. d. Bruijn \& Y. H. Tan (Eds.), Electronic government and electronic participation joint proceedings of ongoing research and projects of IFIP EGOV and ePart 2011 (pp. 77-85). Delft

Charalabidis, Y., Loukis, E., Alexopoulos, C. (2014). Evaluating Second Generation Open Government Data Infrastructures Using Value Models. (HICSS). 47th Hawaii International Conference on System Sciences, 2114-2126

Chun, S. A. and Luna Reyes, L. F. (2012). Editorial - Social media in government. Government Information Quarterly, 29, 441-445.

Constantinides, E., Fountain, S. J. (2008). Web 2.0: Conceptual foundations and marketing issues. Journal of Direct, Data and Digital Marketing Practice, 9(3), 231-244

Criado, J. I., Sandoval-Almazan, R., Gil-Garcia, J. R. (2013). Government innovation through social media. Government Information Quarterly, 30, 319-326.

Davis, T., Mintz, M. (2009). Design features for the social web: The Arcquitecture of Deme. In: Proceedings of 8th International Workshop on Web-Oriented Software Technologies - IWWOST

Dawes, S., \& Helbig, N. (2010). Information strategies for open government: Challenges and prospects for deriving public value from government transparency. Paper presented at the 9th International Conference on e-government (EGOV), Lausanne, Switzerland. 
Ding, L., Peristeras, V., \& Hausenblas, M. (2012). Linked Open Government Data [Guest editors' introduction]. Intelligent Systems, IEEE, 27(3), 11-15. doi: 10.1109/MIS.2012.56

European Commission. (2003). Directive 2003/98/EC of the European Parliament and of the council of 17 November 2003 on the re-use of public sector information Retrieved December 12, 2012, from http://ec.europa.eu/information society/policy/psi/rules/eu/index en.htm.

Executive Office of the President (2009). Memorandum for the Heads of Executive Departments and Agencies: Open Government Directive. Retrieved from. http://www. whitehouse.gov /open/documents/open-government-directive.

Goh, K. Y., Heng, C. S, Lin, Z. (2013). Social media brand community and consumer behavior: Quantifying the relative impact of user- and marketer-generated content. Information Systems Research, 24(1), 88-107

European_Commission. (2011). Digital agenda: Turning government data into gold. Brussels: European_Commission.

Jetzek, T., Avital, M., Bjorn-Andersen, N. (2013). The Generative Mechanismsof Open Government Data. In Proceedings of of the 21st European Conference on Information Systems (ECIS) 2013, Utrecht, The Netherlands.

Margo, M. J. (2012) A Review of Social Media Use in E-Government. Administrative Sciences, Administrative Sciences, 2 , 2, 148-161.

O' Reilly, T. (2007). What is Web 2.0: Design patterns and business models for the next generation of software. Communications and Strategies 1, 17-37.

Pelet, A. (2013) Re-Designing Open Data 2.0. Journal of eDemocracy and Open Government 5(2): 187-199

Poikola, A., Kola, P., \& Hintikka, K. A. (2011). Public data. An introduction to opening information sources. Helsinki, Finland, : Ministry of Transport and Communications.

Pollock, R. (2011). Building the (Open) Data Ecosystem Retrieved September 13, 2013, from http://blog.okfn.org/2011/03/31/building-the-open-data-ecosystem/

Ubaldi, B. (2013). Open Government Data: Towards Empirical Analysis of Open Government Data Initiatives. In N. OECD Working Papers on Public Governance (Ed.): OECD.

Zhang, J., Dawes, S., \& Sarkis, J. (2005). Exploring Stakeholders' Expectations of the Benefits and Barriers of EGovernment Knowledge Sharing. Journal of Enterprise Information Management, 18 (5), 548-567.

Zuiderwijk, A., Janssen, M., Choenni, S., Meijer, R., \& Sheikh_Alibaks, R. (2012). Socio-technical impediments of open data. Electronic Journal of eGovernment, 10(2), $156-172$.

Zuiderwijk, A., Janssen, M., Davis, C., (2014). Innovation with open data: Essential elements of open data ecosystems. Information Polity, 19(1), 17-33, IOS Press

\section{About the Authors \\ Charalampos Alexopoulos}

Charalampos Alexopoulos is a Researcher at the Information Systems Laboratory of the University of the Aegean working on high-level policy making, research and pilot application in FP7. He is a computer science graduate from the University of Peloponnese with MSc in Information Systems Management from the University of the Aegean. His research interest lies in the areas of open data, interoperability and IS evaluation.

\section{Euripidis Loukis}

Euripidis Loukis is Associate Professor of Information and Decision Support Systems at the Department of Information and Communication Systems Engineering, University of the Aegean, Greece. He has also lectured at the University of Thessaly, and at postgraduate programs of the National Technical University of Athens, and the National Academy of Public Administration and. He has extensive experience of national and international research cooperation. His research interests are e-government/e-participation, information systems impact and business value, medical decision support systems.

Yannis Charalabidis

Yannis Charalabidis is Tenured Assistant Professor of e-Government Information Systems at the Department of Information and Communication Systems Engineering, University of the Aegean, Greece. He also serves as the Scientific Director at the Greek Interoperability Centre, hosted at Decision Support Systems Laboratory of the National Technical University of Athens, delivering high quality research in the area of interoperability. He writes and teaches on government service systems, enterprise interoperability, government transformation and citizen participation. 